\title{
Defasagem Idade-Série a partir de distintas perspectivas teóricas
}

\author{
ROSANA RIBEIRO \\ MARIA CRISTINA CACCIAMALI*
}

\begin{abstract}
(1)
Age-grade gap from different theoretical perspectives. The purpose of this article is to analyze the determinants of the age-grade gap based on the human capital theory and some education sociology approaches. The article also shows the range and limitations of the Family Scholarship Transfer Programme (programa Bolsa Familia) in this age-grade gap reduction process. From the investigated theoretical aspects it can be concluded that this Programme would only show long-term effectiveness in the poverty reduction process if supported by at least a combination of programs and actions aimed at improving this educational indicator.
\end{abstract}

Keywords: age-grade gap; human capital; Bolsa Família Programme.

JEL Classification: I25 (Education and Economic Development).

A frequência escolar da população infantojuvenil, entre 7 e 15 anos de idade, não é mais um desafio para as autoridades governamentais brasileiras. Em 2008, segundo dados da PNAD, mais de $90 \%$ de nossas crianças e adolescentes frequentavam a escola. Contudo, a defasagem série-idade ainda permanece como desafio. São considerados em situação de defasagem escolar os alunos que não possuírem no início de cada ano letivo os anos de estudo compatíveis com a sua idade. No mesmo ano de 2008 , variava entre $2 \%$ e $22 \%$ o índice de crianças com 7 e 8 anos de idade que estavam com atraso escolar, enquanto entre os jovens de 15 anos essa proporção atingia $46 \%$. Em geral, os determinantes da defasagem idade-série são: entrada tardia na escola, evasão ou repetência escolar.

\footnotetext{
* Professora Doutora do Instituto de Economia da Universidade Federal de Uberlândia, e-mail: rosanaribeiro@prove.ufu.br; Professora Titular e Livre-Docente da Faculdade de Economia, Administração e Contabilidade da Universidade de São Paulo, e-mail: cciamali@uol.com.br. Submetido: 10/agosto/2011; Aprovado: 4/setembro/2011.
} 
Para a elaboração de políticas públicas educacionais é fundamental o entendimento dos determinantes dos principais fatores que contribuem para defasagem escolar. Neste artigo nos concentramos na defasagem escolar na medida em que esse indicador pode ser considerado uma variável síntese de outros indicadores. Dessa maneira, a melhora na defasagem escolar expressa em alguma medida uma mudança em outros indicadores como entrada tardia na escola, repetência ou evasão escolar.

O fenômeno da defasagem escolar não pode ser reduzido às variáveis socioeconômica das famílias já que a quantidade e a qualidade das escolas, o ingresso no mercado do trabalho, as características individuais observáveis e não observáveis são também determinantes importantes. Contudo, no presente estudo nos concentramos nos determinantes vinculados aos recursos familiares tal como apontados pela teoria econômica convencional e a sociologia da educação. De acordo com Coleman (1993), as variáveis associadas às famílias exercem papel relevante nos indicadores educacionais. A principal contribuição deste artigo se refere ao esforço de interpretar os principais pontos de convergência e divergência entre os teóricos do capital humano, os reprodutivistas e aqueles defensores da ação racional. A partir dessa reflexão podemos apontar os limites e alcances do Programa Bolsa Família que tem como objetivo a superação da pobreza no longo prazo por meio da elevação do nível de escolaridade.

Os adeptos da teoria do capital humano geralmente defendem uma estreita relação entre escolaridade, produtividade e salários. Sob essa ótica, o baixo capital humano se perpetua de geração em geração e origina, portanto, a armadilha da pobreza. As famílias pobres necessitam dos rendimentos de todos os membros que estejam aptos ao trabalho, assim, tão logo quanto possível, suas crianças são compelidas para o trabalho. $\mathrm{O}$ ingresso precoce no mercado de trabalho pode levar ao abandono da escola e ao comprometimento do capital humano dessas crianças. Na fase adulta, essas pessoas receberiam, então, baixos rendimentos e formariam novas famílias pobres. O programa Bolsa família visa melhorar o nível de renda das famílias por meio da transferência do recurso monetário e via suas condicionalidades, tais como frequência escolar das crianças e jovens, superar a pobreza intergeracional. Noutras palavras, o programa se fundamenta na teoria do capital humano e poderia indiretamente contribuir para redução da defasagem escolar na medida em que promoveria estímulos para inserção da criança na idade preconizada na escola, redução da evasão escolar e também levaria o nível de assiduidade dessas crianças em sala de aula e, portanto, melhoraria os patamares daquelas crianças que realizam a transição escolar.

A maioria dos economistas utiliza a teoria do capital humano para explicar as razões individuais do abandono ou prosseguimento na vida escolar. Os estudantes que nem concluíram o ciclo básico e abandonaram à escola seriam portadores de defasagem escolar. A teoria do capital humano se fundamenta em postulados idênticos àqueles que integram o corpo teórico convencional da ciência econômica, quais sejam, os indivíduos são considerados agentes racionais, portanto, deve-se compreender os parâmetros que norteiam as decisões individuais.

Por outro lado, os sociólogos têm uma profusão de teorias que buscam explicar a permanência na escola, bem como o sucesso ou fracasso escolar. Optou-se 
nesse estudo por se concentrar em dois corpos teóricos: a teoria do reprodutivismo e a teoria da ação racional. Um dos principais expoentes da escola reprodutivista é Pierre Bourdieu (1999a, 1999b, 1999c), que advoga como um dos principais fatores que interferem no sucesso ou fracasso escolar a herança cultural familiar. Em sua opinião, a escola não contribui para superar o déficit cultural enfrentado por diversas crianças e adolescentes, ao contrário, as instituições de ensino reproduzem essas diferenças. Bourdieu afirma que a racionalidade econômica postulada pela teoria econômica convencional não emerge em qualquer condição, assim nas famílias com maiores fragilidades econômicas e culturais não vigora essa racionalidade. Noutras palavras, o autor não rechaça inteiramente a possibilidade dos indivíduos nortearem suas ações segundo os preceitos dos economistas ortodoxos.

A teoria sociológica da ação racional, por sua vez, assume que a herança cultural interfere nas habilidades cognitivas, nos estímulos e nas expectativas dos indivíduos e poderia, portanto, influenciar o aproveitamento escolar das crianças, porém somente nas etapas iniciais de estudo. Segundo esses teóricos (dentre eles, Boudon, 1981), as habilidades cognitivas entre os indivíduos que superaram as primeiras dificuldades de aprendizagem são mais homogêneas, assim não se poderia atribuir aos recursos familiares o sucesso ou fracasso nas transições escolares após uma determinada etapa dos estudos. Para os defensores dessa teoria, a permanência na escola e a realização das progressões escolares nas etapas posteriores somente podem ser compreendidas a partir dos parâmetros que orientam as decisões individuais. A teoria do capital humano, portanto, se difundiu inclusive entre algumas vertentes da teoria sociológica, que incorporaram integralmente ou parcialmente seus postulados.

Este artigo é composto de quatro seções. A primeira delas compreende uma reflexão sobre a teoria do capital humano e contém uma subseção com considerações críticas, ao passo que a segunda seção corresponde a uma exposição do pensamento de alguns sociólogos denominados reprodutivistas. A terceira seção se refere à teoria da ação racional que se desenvolveu no interior da sociologia, enquanto a quarta trata dos desdobramentos dessa teoria.

\section{TEORIA DO CAPITAL HUMANO}

O intuito da teoria do capital humano é fornecer os determinantes das "decisões" relativas a frequência ou abandono da escola por parte dos alunos. $\mathrm{O}$ estudante que "opta" por frequentar a escola se candidata à realização da transição escolar, que corresponde à passagem de uma série do ensino para outra. O estudante que frequenta e realiza a progressão escolar prevista, portanto, não se depara com a defasagem idade-série. A frequência escolar é, então, elemento importante, embora não único, para a redução dessa defasagem.

A teoria do capital humano se baseia nos princípios do individualismo metodológico desenvolvidos pela economia neoclássica. Os indivíduos são considerados sujeitos racionais e bem informados sobre a sociedade em que vivem. Em geral, admite-se que uma projeção do futuro é considerada pelo agente econômico no 
momento mesmo de sua decisão econômica. A compreensão dos parâmetros que norteiam as decisões dos agentes é situada no plano microeconômico. Os agentes agem racionalmente para atingir seus fins, realizando um cálculo de maximização da utilidade, ou seja, os indivíduos procuram obter o máximo de resultados favoráveis aos seus objetivos com o mínimo de custos.

Na perspectiva do individualismo metodológico, o entendimento do funcionamento do sistema econômico exige o conhecimento do comportamento que orienta as decisões individuais dos agentes. Por outro lado, o nível macroeconômico resulta do somatório dos comportamentos microeconômicos.

A partir dos anos 1960, a teoria do capital humano ganhou contornos que se estendem aos dias atuais. Gary Becker (1962, 1964), Jacob Mincer (1960) e Theodore Schultz (1961) são os pioneiros dessa vertente que atraiu, e ainda atrai, diversos adeptos ao longo dos anos. Esses autores, apoiados no conceito neoclássico de capital, que corresponde ao estoque de máquinas ou equipamentos e cujas variações representam o investimento, desenvolveram o conceito de capital humano como um estoque de habilidades ou conhecimentos, e suas variações positivas também representam investimento. $\mathrm{O}$ capital humano inclui o nível de educação formal, o conhecimento obtido no local de trabalho, os cuidados médicos necessários para uma boa saúde, o consumo de vitaminas e a aquisição de informações pelos indivíduos sobre o sistema econômico (Becker, 1962, p. 9). Em resumo, o capital humano corresponde às habilidades naturais, como a inteligência, e às habilidades adquiridas, que resultam de uma decisão "voluntária", como frequentar a escola.

$\mathrm{Na}$ perspectiva da teoria econômica convencional e dos defensores do capital humano, as pessoas são movidas pelo autointeresse; assim, o mais adequado seria prestar atenção ao bem-estar de cada pessoa (Sen, 1999). Os teóricos do capital humano pressupõem que os indivíduos se autogerenciam e tomam suas decisões acerca do investimento em capital humano guiados pela busca da maximização de sua utilidade.

A formação educacional das crianças e jovens adolescentes, em geral, é uma decisão da família. Em vista disso, Becker (1962) desenvolve estudos que buscam compreender os principais determinantes das decisões familiares. A família é definida como uma unidade de produção que busca maximizar seu nível de utilidade e decide sobre a oferta de trabalho de seus membros e a maneira como os recursos familiares são utilizados. O nível de utilidade depende do consumo atual da família, bem como do consumo futuro de seus filhos. Uma hipótese adotada, em alguns casos, se refere à existência de um mercado de crédito, ou seja, as famílias podem obter recursos emprestados para investir no capital humano de seus filhos. Nesse caso, os gastos com a formação educacional dos filhos não afeta o consumo atual e, portanto, não depende da renda familiar.

Entretanto, na hipótese de não existir mercado de crédito, os gastos com a educação dos filhos dependerá, sobretudo, dos recursos familiares, embora os recursos governamentais possam aliviar o custo educacional para diversas famílias. A decisão das famílias de arcar com os gastos educacionais, no caso de inexistência de mercado de crédito, depende da renda e do altruísmo dos pais. Becker e Tomes (1986) adotam essa hipótese e buscam compreender o processo de maximização 
da utilidade das famílias nesse contexto. Os autores constatam que ao decidir pela formação escolar das crianças as famílias terão que reduzir seu consumo a fim de investirem no capital humano dos filhos. Por outro lado, o custo desse investimento cresce com o nível de gastos das famílias, e a taxa de desconto utilizada para calcular o benefício futuro, gerado pela elevação do nível de escolaridade dos filhos, também se eleva na medida em que os pais deixam de consumir no presente em favor dos filhos. A partir desses parâmetros se poderia compreender os motivos que levam as famílias a interromperem a trajetória escolar de seus filhos.

Acemoglu e Pischke (2001) desenvolvem um modelo inspirado em Becker e Tomes (1986), que visa estimar o efeito da renda na decisão familiar acerca dos estudos de seus filhos. Para as famílias de renda elevada, a decisão de investir na educação dos filhos depende somente do custo da educação e do seu retorno, enquanto nas famílias das camadas populares, a renda da família ou seu consumo atual também interferem na decisão de investir em capital humano. Em resumo, nas famílias de renda elevada, o investimento na educação dos filhos se efetivará desde que o custo para adquirir educação seja menor que o ganho esperado. Contudo, nas famílias de baixa renda, que são obrigadas a reduzir o consumo presente no momento da decisão acerca dos gastos com a educação de seus filhos, nivelam-se a utilidade atingida com e sem esses gastos.

Outro desdobramento da teoria do capital humano é o modelo do ciclo de rendimentos. Ben-Porath (1967) desenvolveu esse modelo que busca relacionar a decisão de investir em capital humano, sobretudo no ensino formal, e o ciclo de rendimentos ao longo da vida. $\mathrm{O}$ autor ressalta que a elevação do capital humano gera custos e também benefícios, porém os jovens são mais propensos a investir em capital humano porque dispõem de um período de tempo maior para receber os benefícios que poderão ser obtidos com a elevação do nível de ensino formal. Ben-Porath (1967) mostra, a partir de vários dados, que os salários se elevam com a idade até um certo ponto, em função da elevação da produtividade do trabalho que resulta do investimento em capital humano ou do treinamento no local de trabalho, e depois se verifica uma queda nos rendimentos.

Em síntese, os indivíduos ou as famílias decidem racionalmente investir em capital humano considerando determinados parâmetros — custo e beneficio —, e as famílias com crianças e jovens são mais propensas a realizar esse investimento. As famílias que investem no capital humano de seus filhos elevam os rendimentos futuros dessas crianças e jovens. Entretanto, em realidades como a brasileira, crianças sem nenhum custo com a educação e desprezível custo de oportunidades interrompem sua trajetória escolar, inclusive jovens adolescentes também “decidem" sair da escola. Como se pode compreender essa interrupção da vida escolar e, portanto, da possibilidade de realizar as progressões escolares e eliminar a defasagem idade-série, a partir da teoria do capital humano?

Uma possível resposta seria o desconhecimento das famílias acerca dos prêmios salariais obtidos com um nível de escolaridade mais elevado (Neri, 2009). Ou seja, uma parte das famílias tem mais informação que outras - isto é, existem informações assimétricas. Desse modo, algumas famílias com maiores informações 
sobre os benefícios proporcionados por um nível de escolaridade mais elevado "optam" por manterem seus filhos mais tempo na escola.

Outra resposta para a evasão escolar de crianças e jovens se baseia na identificação da situação de pobreza que vigora em muitos casos. Nas famílias pobres, muitas crianças e jovens deixam a escola porque o presente tem um elevado valor e o futuro, na maioria das vezes, não compõe o horizonte que norteia as decisões dessas famílias. Assim, os filhos de famílias pobres deixariam de frequentar a escola não pela ausência de informação associada aos benefícios que o nível de escolaridade carrega, mas pelo valor que o presente assume na vida dessas pessoas. Segundo Ramos (2002, p. 12),

[...] Nas famílias pobres, a taxa de desconto, ou seja, o valor que seus membros outorgam ao presente, é muito elevado. Não tem nenhuma relevância se a mãe de uma criança sabe que, se ela estuda e chega a ser doutor terá uma vida com poucas privações materiais, visto que seu horizonte de tempo pode ser o dia (não tem nada para comer hoje). Nessas circunstâncias, um horizonte de 15 anos é, para ela, o infinito, ou, em termos de valor presente, o valor atual desse hipotético fluxo de renda futuro é próximo de zero.

Esse argumento mostra-se compatível com a hipótese do autointeresse e da racionalidade dos agentes. Nesse caso, as pessoas pobres maximizam seu interesse, entretanto seus parâmetros assumem valores distintos do restante da população em virtude das restrições impostas pela pobreza.

Nas famílias de baixos rendimentos qualquer choque de renda eleva ainda mais a probabilidade da criança ou jovem abandonar precocemente a escola. Vários estudos investigam o efeito de choques transitórios de rendimentos sobre a frequência escolar e concluem que nas famílias de baixos rendimentos o abandono escolar é mais frequente em situações de alterações bruscas dos rendimentos (Duryea, 1998; Neri et al., 2000). Mais uma vez, os parâmetros chaves na decisão de investir em educação formal são o custo e o beneficio dessa decisão. Para a teoria do capital humano em suas diversas variantes, esses são os elementos chaves para a compreensão da interrupção da vida escolar por parte de várias crianças e jovens adolescentes. A evasão escolar impede aqueles que estão fora da escola de realizarem suas progressões escolares e, portanto, de eliminar a defasagem idade-série.

Segundo defensores dessa teoria, o baixo capital humano se perpetua de geração em geração e origina, portanto, a armadilha da pobreza. As famílias pobres necessitam dos rendimentos de todos os membros que estejam aptos ao trabalho, assim, tão logo quanto possível, suas crianças são compelidas para o trabalho. $\mathrm{O}$ ingresso precoce no mercado de trabalho pode levar ao abandono da escola e ao comprometimento do capital humano dessas crianças. Na fase adulta, essas pessoas receberiam, então, baixos rendimentos e formariam novas famílias pobres.

É nesse contexto que o programa de transferência de renda condicionada Bolsa Família - implementado no Brasil busca superar a pobreza no longo prazo, 
por meio de uma assistência financeira às famílias carentes, no intuito de compensar a renda proveniente do trabalho infantil e, com isso, aumentar a permanência das crianças à escola. O objetivo desse programa no longo prazo é contornar a situação de pobreza absoluta por meio da melhora do capital humano das crianças e jovens pobres. Desse modo, a vertente da teoria do capital humano embasa teoricamente o programa Bolsa família.

\section{Considerações críticas sobre a teoria do capital humano}

Os estudos inspirados na teoria do capital humano, que buscam compreender os determinantes das decisões familiares acerca da permanência de seus filhos na vida escolar, baseiam-se nas mesmas premissas que orientam as decisões individuais, tais como a existência do agente racional, o conhecimento perfeito da renda futura, a presença do agente otimizador dos recursos e o autointeresse. Nessa concepção em que as pessoas norteiam suas decisões pelo autointeresse, a complexidade que caracteriza as motivações humanas é eliminada. No modelo convencional, afirma Sen (1999, p. 20), "o comportamento humano [...] baseia(-se) tipicamente em motivos simples e facilmente caracterizáveis”. Noutras palavras, as motivações que norteiam as decisões são tratadas de forma bastante simplificada.

Os teóricos que se apoiam na teoria neoclássica, como os defensores da teoria do capital humano, supõem que as pessoas se comportam racionalmente, e que esse comportamento corresponde ao comportamento real. Porém os indivíduos cometem erros, se confundem etc. De acordo com Sen $(1999$, p. 28$)$, a racionalidade dos agentes é concebida como a consistência interna de suas escolha e com a maximização do seu interesse.

No primeiro caso, a consistência interna corresponde à possibilidade de explicar as escolhas a partir da maximização de alguma relação binária. Sen (1999) argumenta que essa condição não é adequada para estabelecer racionalidade. Diz o autor: "Se uma pessoa fizesse exatamente o oposto daquilo que a ajudaria a obter o que ela deseja, e fizesse isso com impecável consistência interna (sempre escolhendo exatamente o oposto daquilo que aumentaria a ocorrência das coisas que ela deseja e valoriza), essa pessoa não poderia ser considerada racional [...]" (Sen, 1999, p. 29). Enfim, a consistência interna das escolhas não pode ser suficiente para estabelecer a existência do comportamento racional.

A maximização do autointeresse supõe uma correspondência entre as escolhas que uma pessoa faz e o seu interesse. O sujeito racional busca maximizar o autointeresse, assim, as pessoas que não o fazem são irracionais. Como ressalta Sen (1999, p. 31), "a visão da racionalidade como autointeresse implica, inter alia, uma decidida rejeição da concepção da motivação relacionada à ética”.

Na perspectiva de Sen, o ponto decisivo é se existe ou não uma pluralidade de motivações, ou se é unicamente o autointeresse que move os indivíduos. Segundo o autor, mesmo admitindo-se que as pessoas se comportassem de um modo unicamente autointeressado, não seria possível afirmar que elas atingem algum tipo de eficiência. 
Segundo a teoria do capital humano, a decisão individual de elevar o nível de escolaridade se baseia na taxa interna de retorno, que se calcula a partir do valor presente dos custos com a educação e do valor presente dos benefícios de cada ano adicional de estudos. A decisão de investir em educação somente se realiza se os benefícios superarem os custos, que se dividem em diretos e indiretos. Os primeiros custos são medidos pelos gastos com cada ano de estudo, como o pagamento de mensalidade escolar e livros, enquanto os custos indiretos correspondem aos salários não recebidos. Os benefícios, por sua vez, são dados pelo diferencial de salários obtido pelo ano extra de estudo. A decisão dos indivíduos em adquirir um ano a mais de estudo, assim, obedece aos mesmos princípios clássicos do processo de investimento que resulta da comparação dos custos e dos benefícios. A decisão resulta de uma avaliação racional, além do que o indivíduo escolhe a partir da variável com maior valor presente. Porém é difícil imaginar que as pessoas tenham essa possibilidade de escolha; logo, a aplicabilidade da teoria do capital humano exige uma sociedade caracterizada pela igualdade de oportunidades no acesso e na permanência na escola. Cabe ressaltar que a teoria do capital humano, inspirada e criada a partir do individualismo metodológico, padece das mesmas limitações que Sen (1999) apontou na teoria convencional.

\section{Os reprodutivistas}

Os escritos de Bourdieu e outros autores (Bowles e Ginteis, 1976; Bourdieu e Passeron, 1975) são vinculados à teoria da reprodução social da educação, segundo a qual a escola tem a função de selecionar pessoas por meio de valores, e sua função latente consiste em garantir a reprodução das estruturas sociais, particularmente a hierarquia das classes.

Bourdieu (1999a) questiona as previsões liberais que apontavam que a igualdade de oportunidade conduziria à redução das desigualdades educacionais. Para o autor, essa previsão não se confirmou porque existem divergências nas atitudes familiares e desigualdade na herança cultural. Ou seja, algumas crianças e jovens interrompem a vida escolar influenciados por esses parâmetros.

Bourdieu advoga que as aspirações ou as atitudes familiares são decisivas para a continuação da trajetória escolar das crianças.

[...] Em realidade, tudo se passa como se as atitudes dos pais em face da educação das crianças, atitudes que se manifestam na decisão de enviar seus filhos a um estabelecimento de ensino secundário ou de deixá-los na classe fim de estudos primários, de inscrevê-los em um liceu [...] ou em um colégio de ensino geral [...] fossem, antes de tudo, a interiorização do destino objetivamente determinado [...] para o conjunto da categoria social à qual pertencem. Esse destino é continuamente lembrado pela experiência direta ou mediata e pela estatística intuitiva das derrotas ou dos êxitos parciais das crianças do seu meio [...] (Bourdieu, 1999a, p. 47) 
Para o autor, a realidade objetiva limita as aspirações e atitudes das famílias. Nesse sentido, um moral baixo por parte da família engendra uma perspectiva de futuro ruim. Bourdieu sugere que o desejo de ascensão via escola não existe porque as chances objetivas de êxito são reduzidas. Noutras palavras, a estrutura de oportunidades objetivas de ascensão social e das oportunidades de ascensão pela escola limitam as atitudes frente à escola. Essas atitudes explicam a permanência ou o abandono da vida escolar.

Outro determinante apontado por Bourdieu para as desigualdades educacionais se refere à teoria da herança cultural, que corresponde na verdade ao seu conceito de capital cultural. Em diversos trabalhos, Bourdieu (1999a, 1999b, 1999c) explora a conexão entre o conceito de capital cultural, êxito escolar, continuação da trajetória escolar, realização das transições escolares e eliminação da defasagem idade-série.

O capital cultural pode existir de três maneiras: no estado incorporado, que exige inculcação e assimilação pelo receptor; nos bens culturais como quadros, livros dicionários transmissíveis via propriedade jurídica; e no estado institucionalizado, por meio de certificados escolares (Bourdieu, 1999a, p. 74). O autor explica:

[...] cada família transmite a seus filhos, mais por vias indiretas que diretas, um certo capital cultural e um certo ethos [...], sistema de valores implícitos que contribui para definir, entre coisas, as atitudes face ao capital cultural e à instituição escolar. A herança cultural, que difere, sob dois aspectos, segundo as classes sociais, é a responsável pela diferença inicial das crianças diante da experiência escolar e, consequentemente, pelas taxas de êxito. (Bourdieu, 1999a, pp. 41-42).

Como se nota, existe um entrelaçamento entre as atitudes familiares e o capital cultural. Bourdieu ressalta ainda que existe uma parcela altamente rentável da herança cultural fundamental para o êxito escolar, que são as informações sobre a vida universitária, a facilidade de expressão verbal e a cultura livre, porém tais aquisições ocorrem fora dos muros escolares. As crianças inseridas em famílias que têm reduzida herança cultural, portanto, são mais propensas a não possuírem meios culturais, como hábitos de leitura, familiaridade com outros idiomas, recursos que podem ajudá-las a atingir um elevado nível de escolaridade. Em geral, os indicadores de capital cultural familiar utilizados são o nível educacional dos pais e os bens econômicos, embora um não necessariamente assegure o outro.

As famílias que têm elevada herança cultural podem transmitir informações que são importantes para orientar seus filhos ao longo de seu percurso escolar. A título de exemplo, as famílias que são mais bem informadas das possibilidades e exigências da trajetória escolar estimulam seus filhos a investirem mais na educação. Ressalte-se que Bourdieu também concebe a assimetria de informação como um dos determinantes do fracasso ou abandono da vida escolar. Embora, no caso desse autor, essa assimetria de informações se deva à desigualdade na distribuição da herança cultural. 
$\mathrm{Na}$ visão de Bourdieu, a escola não representa uma possibilidade de superar as desigualdades de herança cultural, na verdade ela conservaria a ordem social ao ignorar, no âmbito dos conteúdos do ensino que transmite, os diferenciais culturais entre as crianças das diferentes classes sociais. Além disso, a escola induziria as pessoas a almejar uma vida escolar relacionada com a sua posição social e, portanto, legitimaria as desigualdades escolares.

Bourdieu é um crítico da teoria do capital humano na medida em que advoga que o habitus racional é produto de uma condição econômica particular, definida a partir da posse do capital econômico e cultural necessário para se perceber as oportunidades potenciais oferecidas (Bourdieu, 1999c, p. 91). Todavia, a competência econômica ou arte de avaliar e perceber as chances somente são adquiridas em certas condições sociais.

Para Bourdieu (1999c, p. 94), as classes populares e médias não dispõem de informações suficientemente atualizadas para

[...] conhecer a tempo as apostas a serem feitas, nem de capital econômico suficientemente importante para suportar a espera incerta dos ganhos financeiros, nem tampouco de um capital social suficientemente grande para encontrar uma saída alternativa em caso de fracasso [...].

As camadas populares e médias, assim, não reúnem os elementos necessários para a emergência de uma racionalidade econômica. Nota-se que neste texto Bourdieu não questiona frontalmente a possibilidade de emergência dessa racionalidade.

O mecanismo de reprodução a que a escola conduz, defendido por Bourdieu, não se sustenta em períodos de longa duração, marcados por expansão educacional e elevação das taxas de escolarização inclusive entre os filhos das famílias de camadas populares. Muitos críticos (Goldthorpe, 1996) rejeitam a ideia de que as crianças das famílias com menores vantagens culturais são excluídas ou mesmo eliminadas do sistema educacional. Outro ponto crítico no raciocínio desenvolvido por Bourdieu é a circularidade: a baixa herança cultural se deve ao contato incipiente com a escola, que se justifica por outro lado pelo baixo capital cultural.

Em resumo, Bourdieu defende que a herança cultural e as atitudes das famílias são os determinantes centrais da permanência na escola, do êxito escolar, da realização das transições escolares e da eliminação da defasagem idade-série por parte das crianças. A estrutura objetiva das oportunidades e o capital cultural influenciam as atitudes familiares em relação à trajetória escolar. Além disso, a baixa herança cultural impede que as famílias das camadas populares tenham informações importantes sobre os investimentos necessários ao longo da vida escolar dos filhos, bem como cerceia a possibilidade do surgimento, no seio familiar, da racionalidade econômica defendida pela teoria do capital humano.

Nos trabalhos empíricos utiliza-se como medida do capital cultural das famílias o nível de escolaridade de seus membros, no entanto em Bourdieu esse conceito é mais amplo. Os economistas, por sua vez, em suas pesquisas denominam os anos de estudo de capital humano. Existe uma correlação entre nível de renda e 
capital cultural ou humano, entretanto a existência do capital cultural não determina necessariamente a renda familiar (capital econômico). Em geral, se admite que o nível de escolaridade mais elevado dos pais pode exercer diversas influências na educação dos filhos, por meio de vários canais como maior acesso aos livros, maior nível de informação acerca dos benefícios dos anos de estudo, expectativa dos pais em relação ao futuro escolar dos filhos, melhor preparo dos pais para ajudar os filhos nas tarefas escolares, maior acesso a museus, concertos etc.

\section{Teoria da Ação Racional}

O modelo de Boudon tem inspiração na teoria econômica baseada no individualismo metodológico. Nessa concepção, é crucial entender os parâmetros que orientam as ações dos indivíduos os quais, como apontado anteriormente, agem racionalmente para atingir seus fins.

Boudon (1981) concorda com Keller e Zavollini $(1962,1964)$ que as aspirações dos indivíduos, inclusive no tocante ao nível educacional, dependem de sua posição social. Para Keller e Zavollini (1962,1964), se dois indivíduos em posições sociais distintas desejam atingir posições sociais diferentes por meio da escola, isso não se deve a divergências ou diferenças nos valores outorgados aos diplomas escolares. A significação conferida pelos indivíduos aos diversos níveis escolares variam em função da posição social dos indivíduos, afirmam os autores. As diferenças de aspiração, portanto, são interpretadas em termos estruturais, na medida em que resultam das diferenças típicas de posição de classe.

Boudon (1981) também aceita os argumentos de Parsons (1970) sobre a relação entre nível de escolaridade e solidariedade familiar. Para Parsons, os indivíduos situados em posições sociais distintas e que almejam o mesmo nível de escolaridade para seus filhos enfrentam custos distintos, que são compostos inclusive por custos não econômicos. Esse autor considera a família como importante núcleo de solidariedade que busca preservar esse vínculo entre seus membros, no entanto a diferença cultural entre pais e filhos é um fator que ameaça a solidariedade familiar. $\mathrm{O}$ autor explica a proximidade ou o afastamento dos membros familiares apoiado exclusivamente no nível cultural, e despreza outros elementos decisivos para o processo de aproximação e solidariedade entre os membros familiares, como a identificação estabelecida por meio de mecanismos da psique. Segundo Parsons, muitas famílias, induzidas por esses custos não econômicos, interferem nas ambições escolares dos filhos no intuito de preservar o núcleo de solidariedade familiar.

Por outro lado, Boudon considera que uma teoria baseada nos determinantes da ação dos indivíduos se revela adequada para explicar a continuação da trajetória escolar, embora admita que essa teoria somente possa ser aplicada a partir de uma determinada etapa da vida escolar, que corresponde a uma fase em que a criança já desenvolveu as habilidades básicas que, por sua vez, são influenciadas pela herança cultural. Noutras palavras, as etapas iniciais da vida escolar geram desafios e as crianças que os superam reúnem as habilidades necessárias para persistir na trajetória escolar. Para o autor, mudanças nas estratégias pedagógicas 
têm maior possibilidade de impactar sobre as desigualdades educacionais, caso sejam implementadas nos níveis escolares iniciais. Boudon (1981) admite que nessa etapa certos fatores sejam importantes para o desenvolvimento das habilidades, como a herança cultural, os fatores psicológicos e genéticos. No caso do sistema educacional brasileiro, o diagnóstico realizado por Boudon se revela importante na medida em que sinaliza os caminhos que são necessários percorrer para evitar o abandono escolar que ainda se verifica no ensino fundamental. Uma aposta em estratégias pedagógicas que incluam a valorização do professor e mecanismos que possam mitigar as diferenças de herança cultural nas crianças das camadas populares poderia contribuir para reduzir a evasão escolar. Rios-Neto et al. (2003) afirmam que, no Brasil, os determinantes maternos e paternos são mais importantes para a progressão na $1^{a}$ série do que na $5^{\text {a }}$ série do ensino fundamental. Além disso, os autores apontam que existe um efeito de substituição entre a escolaridade média dos professores e a escolaridade materna e recomendam que bons professores sejam, portanto, alocados nas séries iniciais do ensino fundamental, no intuito de compensar as deficiências da herança cultural dos pais. Essa seria uma estratégia para superar as dificuldades enfrentadas pelas crianças oriundas das camadas populares.

Segundo defende Boudon (1981), podemos considerar o enfoque da teoria da ação racional adequado para os indivíduos que sobreviveram às dificuldades escolares iniciais. Ou seja, a partir dessa etapa, as escolhas são melhor compreendidas pelo uso da teoria da ação racional. Os teóricos da ação racional afirmam que os indivíduos, ao final de cada etapa escolar, fazem a escolha de permanecer na vida escolar e consideram nessas decisões suas posições sociais, os custos e os benefícios antecipados e diferenciados. O beneficio antecipado em persistir na vida escolar é tanto mais elevado quanto mais próximo está o indivíduo, por sua posição social, dos níveis mais elevados da estratificação social. Por outro lado, o custo antecipado é mais elevado quanto pior for a posição social do indivíduo.

Os indivíduos em cada posição social enfrentam riscos distintos em suas decisões sobre a vida escolar. $\mathrm{Na}$ apreciação desses riscos exercem influências fatores como a idade da criança e/ou aprovação na série escolar. Nota-se que os indivíduos obedecem, portanto, a um processo de decisão racional cujo parâmetro é a posição social, na medida em que essa posição dá um significado distinto ao benefício, ao risco e ao custo da aquisição de determinado nível de estudo.

Em resumo, Boudon defende que as desigualdades educacionais podem ser explicadas em termos dos custos e benefícios individuais, a partir de uma determinada etapa da vida escolar. Os elementos centrais da teoria do capital humano se encontram presentes na teoria da ação racional desenvolvida pioneiramente por Boudon.

\section{Desdobramentos da Teoria da Ação Racional}

A teoria da ação racional teve ampla difusão entre os sociólogos, contudo diversos autores, como Goldthorpe (1996), defendem que essa teoria não corresponde a um corpo teórico único, mas contempla uma variedade de interpretações acerca dos 
determinantes das decisões de frequentar a escola. Pelo menos pontos podem diferenciar as ramificações que derivaram da teoria da ação racional: 1 a maior ou menor importância atribuída à racionalidade dos agentes; 2 a tentativa de desenvolver uma teoria da ação racional mais geral ou, em outros casos, mais específica.

Ancorado na Teoria da Ação Racional, Goldthorpe (1996) afirma que as ações e escolhas dos indivíduos são condicionados pela distribuição de oportunidades e pelas restrições que cada classe social enfrenta. Para o autor, os indivíduos podem ser alocados em duas classes sociais, sendo que na primeira classe existem maiores vantagens, inclusive econômica, e na segunda prevalecem menores vantagens. Essa divisão se baseia no tipo de ocupação profissional exercida pelos pais.

Goldthorpe (1996) adota duas suposições gerais: primeiro assume que os diferenciais educacionais operam por meio do efeito primário e do efeito secundário, nesse aspecto claramente influenciado por Boudon. O efeito primário reúne os elementos que são capazes de influenciar a distribuição das habilidades entre as crianças nos primeiros anos de estudo, enquanto o efeito secundário compreende os parâmetros que condicionam as escolhas que as pessoas fazem. O efeito secundário, que corresponde ao desenvolvimento da Teoria da Ação Racional, atuaria quando os indivíduos ultrapassaram as transições iniciais e, portanto, atingiram a base de habilidades necessárias. A segunda suposição se refere à adoção da hipótese da escolha racional, ou seja, as decisões dos indivíduos a respeito da trajetória educacional se baseiam numa avaliação dos custos e benefícios das possíveis alternativas que se apresentem. Mais uma vez adotam-se hipóteses: os indivíduos compreendem a sociedade na qual estão inseridos e são capazes de predizer os resultados de suas decisões. A avaliação dos custos e benefícios das possíveis alternativas depende inclusive das restrições e oportunidades com que as pessoas se deparam.

A partir dessas hipóteses, o autor desenvolve um modelo das decisões educacionais que estabelece os parâmetros para decisões racionais das pessoas, quais sejam: 1 - os custos de permanecer na escola; 2 - as chances de sucesso se a pessoa permanecer na escola; e 3 - o valor que a pessoa estabelece para os resultados educacionais.

Goldthorpe desenvolve três mecanismos que atuam sobre as preferências individuais na decisão de permanecer ou não na escola. $\mathrm{O}$ primeiro postula que as pessoas evitam uma mobilidade social descendente. $\mathrm{O}$ segundo admite que existem diferenciais de habilidades e de expectativas entre as classes sociais. O terceiro mecanismo assume a existência de custos educacionais, e que os recursos familiares afetam as decisões educacionais.

Segundo Goldthorpe, os diferenciais educacionais persistem em etapas mais avançadas das transições educacionais, como no ensino superior, em função da estabilidade do custo e do benefício nas diferentes classes sociais. A título de exemplo, nas classes menos favorecidas as flutuações de renda são mais frequentes. Isso exige maior prudência no cálculo dos custos educacionais. Além do que, entre os trabalhadores menos qualificados a curva que relaciona renda e idade tem uma queda ao longo do tempo mais próxima do fim do ciclo escolar compulsório, ao contrário da curva dos trabalhadores mais qualificados. 
A partir de seu modelo, Goldthorpe (1996) desenvolve as seguintes conclusões:

1. o nível de educação desejado pelos estudantes é no mínimo o nível alcançado pelos seus pais;

2. estudantes do gênero masculino e aqueles de famílias com maiores níveis de escolaridade têm em média melhor desempenho escolar do que os estudantes do gênero feminino e de famílias com menores níveis educacionais;

3. estudantes do gênero masculino e aqueles de famílias com maiores níveis de escolaridade têm maiores expectativas de sucesso do que os estudantes do gênero feminino e de famílias com menores níveis educacionais;

4. Quanto mais elevada a renda dos pais, maior a probabilidades das crianças e jovens ingressarem em cursos superiores;

5. os diferenciais educacionais em termos de classe e gênero se reduzem na Irlanda, quando se controlam as aspirações educacionais, o desempenho escolar, a expectativa de sucesso e a renda familiar.

Para Goldthorpe, o mecanismo de aversão ao risco de uma mobilidade descendente é central na decisão de permanecer na escola. Essa hipótese se articula com a importância atribuída à tentativa dos estudantes de obter no mínimo o nível educacional dos pais.

\section{NOTAS CONCLUSIVAS}

As diversas perspectivas teóricas aqui apresentadas analisam a importância de fatores econômicos, sociais e culturais na permanência dos estudantes na vida escolar, bem como a influência desses parâmetros no desempenho escolar. Economistas convencionais buscam na teoria do capital humano um suporte para compreender por que diversas crianças ou jovens não frequentam a escola na idade escolar e, portanto, enfrentarão a defasagem escolar. Para esses teóricos, o elemento central é o nível de renda da família, na medida em que existem custos diretos e indiretos com a escolarização. A permanência ou abandono da vida escolar resulta do confronto que as famílias realizam entre os benefícios e custos dessas opções. Os sociólogos defensores da teoria da ação racional também advogam que a partir de determinada etapa do ensino prevalece entre as famílias uma lógica de comparação entre custo e benefício em suas decisões acerca da permanência de suas crianças e jovens na escola. Contudo, os parâmetros que influenciam esses custos e benefícios não se restringem ao nível de renda, e apontam elementos como o valor atribuído aos resultados educacionais.

Bourdieu, por sua vez, desenvolve um corpo teórico que auxilia no entendimento não somente da frequência escolar, mas também do desempenho escolar das crianças. O autor defende que a escola cumpre um papel de reprodução social, no entanto outros estudiosos questionam e refutam esse papel atribuído à escola. À parte a polêmica, nos interessa aqui os elementos que Bourdieu aponta para a com- 
preensão do atraso escolar, como a herança cultural das famílias e suas atitudes ante o sistema educacional. O autor, diferentemente dos teóricos do capital humano que ressaltam a importância dos anos de estudo, tem uma concepção ampla de capital cultural, que corresponde a um sistema de valores, informações, vida cultural, educação formal, hábitos e atitudes das famílias. As crianças e jovens inseridos em famílias com déficit de capital cultural terão trajetória escolar distinta daqueles inseridos em famílias com elevada herança cultural. Bordieu sugere que as crianças e jovens que têm uma vida escolar marcada pelo fracasso exigem um conjunto de ações que possam compensar os déficits culturais, sociais e econômicos. $\mathrm{O}$ autor nos permite, a partir de um olhar para as características socioeconômicas e culturais das famílias, pensar as necessidades efetivas dessas crianças e o importante papel que a escola deve cumprir em face dessas carências. Noutras palavras, a permanência na escola, a realização das transições escolares, a redução da repetência e a eliminação da defasagem idade-série exigem um conjunto de ações que não podem ser reduzidas à mera transferência de renda para as famílias pobres, que não compensaria os outros déficits de recursos familiares igualmente importantes na vida escolar das crianças. Boudon (1981) concordaria com os argumentos de Bourdieu, no entanto restringiria sua validade para as etapas iniciais da vida escolar. À parte a polêmica, existe um consenso sobre a importância da herança cultural para o êxito da trajetória escolar das crianças, ainda que somente na etapa inicial. Ou seja, é importante que existam mecanismos de compensação desse déficit na vida escolar das crianças pobres.

A partir desse debate podemos inferir que os programas transferência de renda condicionados que não se encontram articulado a nenhum outro que busque superar os diversos déficits de recursos entre as famílias pobres tem reduzida chances de contribuir para mitigar a defasagem idade-série entre crianças e jovens, em especial no caso brasileiro o Programa Bolsa família. É necessária, portanto, uma reformulação do programa de modo a inseri-lo em um projeto que busque elevar o nível de escolaridade de crianças e jovens por meio da melhora de sua defasagem escolar e que, portanto, os ajude na superação de seus déficits. A ajuda financeira concedida às famílias pobres se revela uma condição necessária, mas insuficiente para a obtenção da melhora dos indicadores educacionais entre as crianças e jovens pobres e, portanto, para a superação da pobreza no longo prazo. Noutras palavras, a transposição da pobreza exige uma estratégia de desenvolvimento que contemple elevação do nível escolaridade, geração de bons empregos, políticas industrial e de inovação.

\section{REFERÊNCIAS BIBLIOGRÁFICAS}

ACEMOGLU, D.; PISCHKE, J. (2001). “Changes in the wage structure, family income, and children's education". European Economic Review, n. 45: 890-904.

BECKER, J. (1962). "Investment in human capital: A theoretical analysis". The Journal of Political Economy, v. 70, n. 5:9-49. Disponível em: <http://www.jstor.org/stable/1829103>. Acesso em: 20 maio. 2008. 
BECKER, G. S. (1964). "Human Capital: A Theoretical and Empirical Analysis with Special Reference to Education". National Bureau of Economic Research. Published by NBER, 1964. 269 p.

BECKER, G. S.; TOMES, N. (1986). "Human Capital and the Rise and Fall of Families". Journal of Labor Economics, v. 4, n. 3: S1-S39.

BECKER, S. O.; ICHINO, A. (2002). "Estimation of Treatment Effects Based on Propensity Score". The Stata Journal, n.4: 358-377.

BEHRMAN, J.; KNOWLES, J. (1999). "Household income and child schooling in Vietnam". The World Bank Economic Review, v. 13, n. 2: 211-256.

BEN-PORATH, Y. (1967). "The production of human capital and the life of earnings". Journal of Political Economy, Universitary of Chicago Press, v. 75, n. 4: 352-36.

BOUDON, R. (1981). A Desigualdade das Oportunidades: A Mobilidade Social nas Sociedades Industriais. Brasília: Editora Universidade de Brasília.

BOURDIEU. P. (1999a). "A escola conservadora: as desigualdades frente à escola”. In: NOGUEIRA, M.A.; CATANI, A. (Org.). Escritos de Educação. Petropólis: Vozes: 39-64.

BOURDIEU. P. (1999b). “O capital social — notas introdutórias”. In: NOGUEIRA, M.A.; CATANI, A. (Org.). Escritos de Educação. Petropólis: Vozes, 1999b: 65-70.

BOURDIEU. P. (1999c). "Os três estados do capital cultura". In: NOGUEIRA, M.A.; CATANI, A. (Org.). Escritos de Educação. Petropólis: Vozes: 71-80.

BOURDIEU, P.; PASSERON, J.C. (1975). A Reprodução: Elementos para uma Teoria do Sistema de Ensino. Rio de Janeiro: Francisco Alves, 1975.

BOWLES, S; GINTIS, H. (1976). Schooling in Capitalism America. New York: Basic Books.

COLEMAN, J. S.(1993). Equality and Achievement in Education. Boulder, CO: Westview Press.

DURYEA, S. (1998). Children's Advancement Trough School in Brazil: The Role of Transitory schoks to household income. Banco Interamericano de Desarrollo. Documento de Trabajo, 376.

GOLDTHORPE, J. H. (1996). "Class analysis and reorientation of class theory: the case of persisting differentials in education attainment". British Journal Sociology, v.47, n.3: 481-505.

KELLER, S.; ZAVALLONI, M. (1962)."Classe sociale, ambition et réussite”. Sociologie du Travail: $1-14$.

KELLER, S.; ZAVALLONI, M. (1964). “Ambition and social class: a respecification”. Social Forces, v. 43: 58-70.

LEON, F. L. L.; MENEZES-FILHO, N. A. (2002). "Reprovação, avanço e evasão escolar no Brasil”. Pesquisa e Planejamento Econômico, v.32, n.3: 417-451.

MINCER, J. (1958). "Investment in human capital and personal income distribution”. The Journal of Political Economy, v. LXVI, n. 4, p. 281-302, Aug. 1958.

NERI, M. C.; Gustafsson-Wright, E.; Sedlacek, G.; Costa, D. R.; Pinto, A. (2000). Microeconomic Instability and Children's Human Capital Accumulation: The Effects of Idiosyncratic Shocks to Father's Income on Child Labor, School Drop-outs and Repetition Ratesin Brazil. 2000. Disponível em: <http://virtualbib.fgv.br/dspace/handle/10438/873>. Acesso em: 18 abr. 2002

NERI, M. C. (2009). Motivos da evasão escolar. Disponível em: <http://www.fgv.br/ cps/tpemotivos/>. Acesso em: 18 dez. 2009.

PARSONS, T. (1970). "Equality and inequality in modern society, or social stratification revisited". Sociology Inquiry, v. 40, n.2: 13-72, 1970.

RAMOS, C. A. (2002). Teoria do Capital Humano. Curso de Economia do Trabalho. Brasília: UNB. Disponível em: <http://www.carlosalberto.pro.br>. Acesso em: 10 nov. 2002.

RIOS-NETO, E. L. G.; CÉSAR, C. C.; RIANI, J. L. R. (2002). “Estratificação educacional e progressão escolar por série no Brasil”, Pesquisa e Planejamento Econômico, v. 32, n. 3: 395-415.

SEN, A. (1999). Sobre ética e economia. São Paulo: Schwarcz. 